\title{
Efeito da acidificação de matriz sobre a petrofísica de rochas carbonáticas
}

Marianna Dantas da Silva ${ }^{1}$, José Agnelo Soares ${ }^{1}$, Analice Lima ${ }^{2}$

1 UFCG, ${ }^{2}$ UFPE
Copyright 2016, SBGf - Sociedade Brasileira de Geofísica

Este texto foi preparado para a apresentação no VII Simpósio Brasileiro de Geofísica Ouro Preto, 25 a 27 de outubro de 2016. Seu conteúdo foi revisado pelo Comite Técnico do VII SimBGf, mas não necessariamente representa a opinião da SBGf ou de seus associados. E proibida a reprodução total ou parcial deste material para propósitos comerciais sem prévia autorização da SBGf.

\section{Resumo}

Amostras carbonáticas naturais e artificiais foram analisadas quanto às suas propriedades petrofísicas antes e após um processo de acidificação de matriz. As propriedades investigadas foram a porosidade, a densidade de grãos e total, a permeabilidade e as velocidades de propagação das ondas elásticas. Antes da acidificação seis amostras, sendo duas naturais e quatro artificiais, foram analisadas. Após a acidificação, uma amostra natural e quatro artificiais foram investigadas. Para todas as amostras houve aumento das porosidades medidas após a acidificação. Antes da acidificação uma amostra natural apresenta densidade de grãos $\left(\rho_{g}\right)$ compatível com dolomito, e outra, com calcário. As amostras artificiais apresentaram $\rho_{\mathrm{g}} \approx 2,6$ $\mathrm{g} / \mathrm{cm}^{3}$. Após a acidificação uma amostra natural apresentou $\rho_{\mathrm{g}}$ compatível com dolomito, duas artificiais com calcário e outras duas artificiais com $\rho_{\mathrm{g}} \approx 2,6 \mathrm{~g} / \mathrm{cm}^{3}$. As amostras naturais apresentaram porosidade de $20 \%$ e de $25 \%$, antes e após a acidificação. As permeabilidades foram $2 \mathrm{mD}$ e $9,5 \mathrm{mD}$, antes e após a acidificação. Nas amostras naturais houve a redução das velocidades de ondas P, VS1, VS2, mas as artificiais apresentaram velocidades ligeiramente superiores. Houve redução dos valores dos módulos elásticos da amostra natural em relação aos da primeira análise. Para as amostras artificiais os módulos elásticos se mantiveram aproximadamente constantes. Quanto à razão de Poisson e ao grau de anisotropia, não houve alterações significativas, as amostras tendem a apresentar um aumento da razão de Poisson com o aumento da porosidade e são isotrópicas.

\section{Introdução}

Dentre os métodos de recuperação avançada que visam aumentar a taxa de recuperação em reservatórios carbonáticos destaca-se a acidificação de matriz (Economides et al, 2009). O objetivo de tal processo é aumentar a permeabilidade do sistema pelo aumento e/ou desobstrução dos poros e das gargantas de poros.

Neste trabalho foram investigados os efeitos do processo de acidificação de matriz sobre as propriedades petrofísicas de amostras carbonáticas. Para tanto foram medidas as propriedades antes e após a acidificação, tanto em amostras de rochas naturais, quanto em amostras artificiais.
As amostras naturais são compostas por dois dolomitos e um calcário. Essas amostras foram extraídas das formações Maria Farinha e Gramame, respectivamente. Ambas ocorrentes na Bacia Pernambuco-Paraíba. As quatro amostras artificiais estudadas são compostas por uma massa prensada de farinha de conchas calcárias. Todas as amostras foram investigadas antes e após a aplicação da acidificação de matriz.

As propriedades petrofísicas analisadas foram a porosidade, a densidade de grãos e total, a permeabilidade e as propriedades elásticas. Trabalhos anteriores (Wang \& Nur, 2000; Avseth et al, 2005) têm demonstrado que tratamentos similares com injeção de ácido ou $\mathrm{CO}_{2}$ provocam alterações nas propriedades petrofísicas de rochas carbonáticas, especialmente nas velocidades elásticas, as quais podem ser detectadas por métodos indiretos de investigação, como por exemplo a sísmica 4D.

\section{Metodologia}

$\mathrm{Na}$ técnica de estimulação de poço por acidificação de matriz uma solução ácida é injetada na formação com o objetivo de dissolver alguns dos minerais presentes, e assim aumentar a permeabilidade na vizinhança do poço. No caso de rochas carbonáticas o ácido utilizado é principalmente 0 ácido clorídrico. 0 tratamento de acidificação de matriz injeta ácido sob pressão inferior a necessária para a indução de fraturas na rocha (Economides et al, 2009). Neste trabalho a técnica de acidificação de matriz foi aplicada a amostras de rochas carbonáticas sintéticas e naturais.

As amostras de rocha analisadas no Laboratório de Petrofísica da UFCG passam por duas etapas: primeiro a preparação dos plugues, que consiste na serragem e retificação, secagem, pesagem e medição de suas dimensões; e numa segunda etapa, a realização dos ensaios propriamente ditos.

Os ensaios de porosidade, densidade e permeabilidade foram realizados no equipamento Ultraporoperm 500 (Figura 1), o qual utiliza a lei de Boyle-Mariotte para medição da porosidade e densidade, e a lei de Darcy para medição da permeabilidade (Tiab \& Donaldson, 2004). Este equipamento utiliza gás nitrogênio. As medidas de porosidade e de densidade são realizadas sob pressão e temperatura ambientes. A permeabilidade é medida sob temperatura ambiente e pressão confinante de 500 psi.

As propriedades elastodinâmicas das rochas foram medidas no equipamento Autolab 500 (Figura 2), sob temperatura ambiente e pressões confinantes efetivas entre 5 e $20 \mathrm{MPa}$. O equipamento mede as velocidades 
de propagação das ondas $\mathrm{P}$ e $\mathrm{S}$ na direção do eixo dos plugues cilíndricos, sendo que são registradas duas ondas S com polarizações mutuamente perpendiculares (no plano perpendicular ao eixo do plugue). A partir das velocidades elásticas e da densidade total das amostras, calculam-se os módulos elásticos (Bourbié et al, 1987; Mavko et al, 2003).

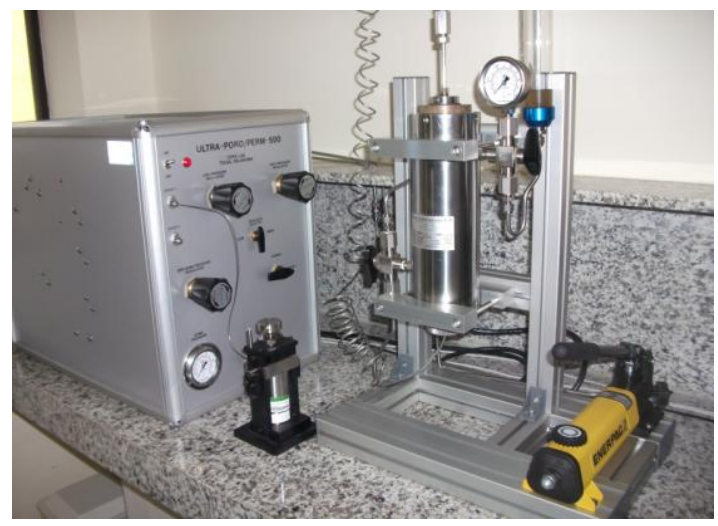

Figura 1 - Equipamento Ultraporoperm 500.

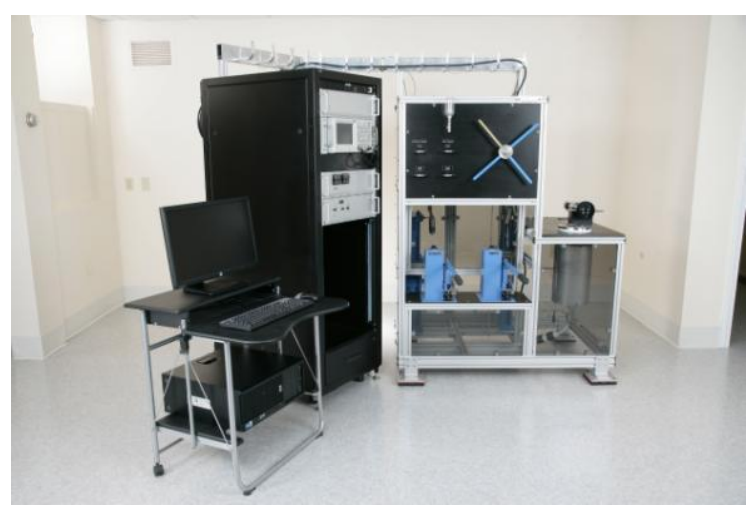

Figura 2 - Equipamento Autolab 500.

\section{Resultados}

A Figura 3 indica que as amostras naturais apresentam densidade de grãos compatíveis com dolomito e calcário, e que estas densidades não foram alteradas após o processo de acidificação. Já as amostras artificiais, que apresentavam densidade de grãos próxima a $2,6 \mathrm{~g} / \mathrm{cm}^{3}$ antes da acidificação, após esse processo, duas delas apresentaram valores de densidade de grãos próximos a $2,7 \mathrm{~g} / \mathrm{cm}^{3}$, enquanto as outras duas se mantiveram inalteradas. Quanto à porosidade, esta apresentou incremento tanto para as amostras naturais quanto para as artificiais.

A Figura 4 apresenta a relação entre a densidade total e a porosidade. A linha cheia corresponde ao ajuste linear estabelecido para as amostras artificiais antes da acidificação, e a linha tracejada para as amostras após o processo. Observa-se que duas amostras se mantém próximas à linha cheia após a acidificação, enquanto outras duas se encontram acima dessa linha. Este é o efeito da mudança na densidade de grãos, como observado na Figura 3. Devido ao reduzido número de amostras naturais, não foram construídas as linhas de tendência para estas amostras. No entanto pode-se observar que todas elas se mantêm ao longo de uma mesma relação linear, isso ocorre porque não houve variação significativa na densidade grãos dessas amostras.

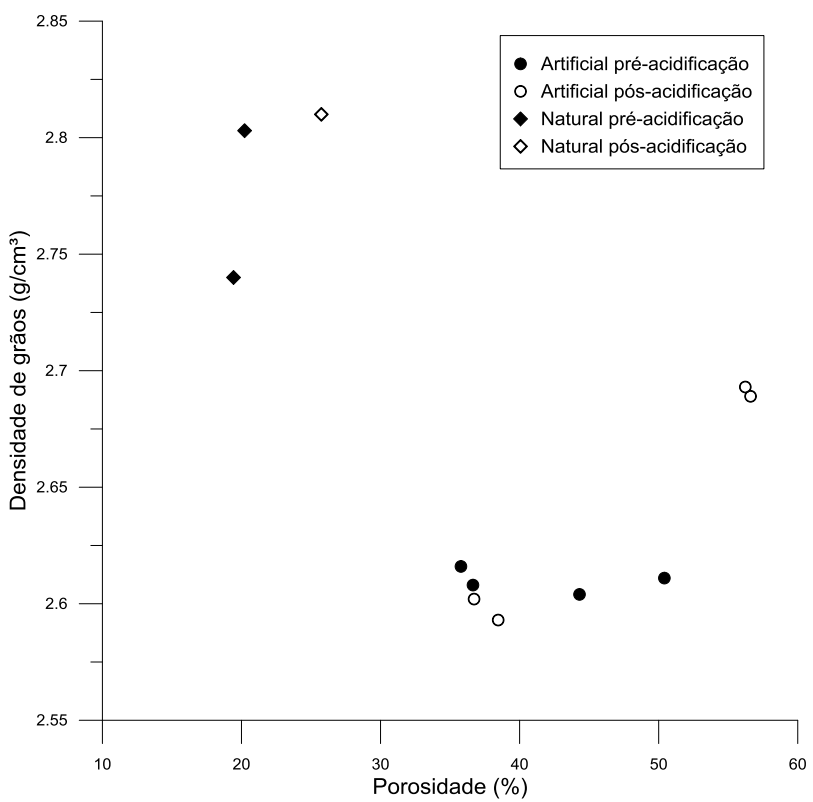

Figura 3 - Relação entre densidade de grãos e porosidade antes e após a acidificação.

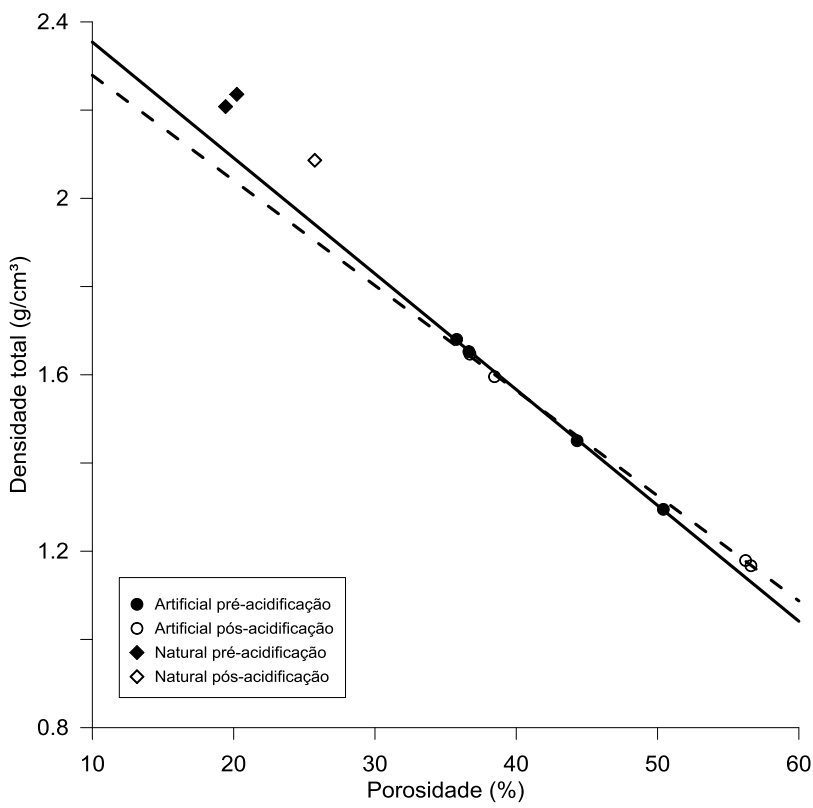

Figura 4 - Relação entre densidade total e porosidade antes e após a acidificação. 
$\mathrm{Na}$ Figura 5 é apresentada a relação entre a permeabilidade e a porosidade, antes e após a acidificação de matriz. As setas indicam o efeito da acidificação sobre estas propriedades, indicando um expressivo aumento na permeabilidade e aumento da porosidade, especialmente no caso das amostras naturais. Na Figura 5 são apresentadas apenas duas amostras artificiais pós-acidificação porque, devido a sua baixa resistência mecânica, não apresentavam condições para o ensaio de permeabilidade.

A Figura 6 apresenta a relação entre a velocidade da onda $\mathrm{P}\left(\mathrm{V}_{\mathrm{P}}\right)$, medida sob pressão confinante de $20 \mathrm{MPa}$, e a porosidade. Pode-se observar que houve uma redução substancial na velocidade da onda $P$ para as amostras naturais e um aumento considerável nas velocidades da onda $\mathrm{P}$ das amostras artificiais. $\mathrm{O}$ mesmo comportamento se observa para o caso das ondas $\mathrm{S}\left(\mathrm{V}_{\mathrm{S} 1}\right.$ e $V_{\mathrm{S} 2}$ ), como mostrado nas figuras 7 e 8 .

A Figura 9 mostra que a anisotropia da onda $S$ está limitada a cerca de $2 \%$, independentemente do tipo de amostra e do processo de acidificação.

As figuras 10 e 11 indicam que a taxa de variação das velocidades das ondas $\mathrm{P}$ e S com a pressão confinante é praticamente insensível ao processo de acidificação, embora as velocidades sejam alteradas pela acidificação.

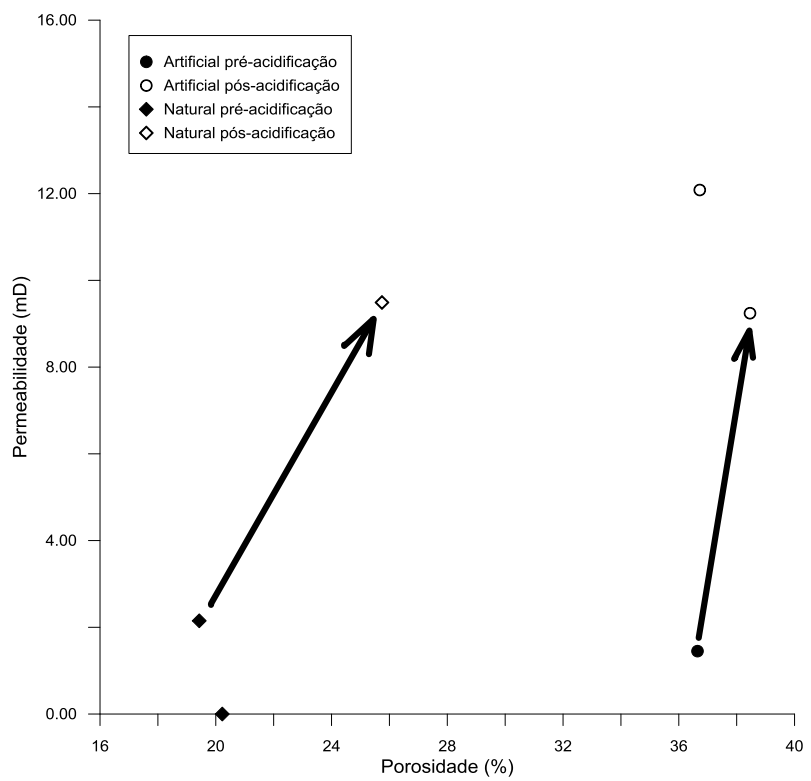

Figura 5 - Relação entre permeabilidade e porosidade antes e após a acidificação.

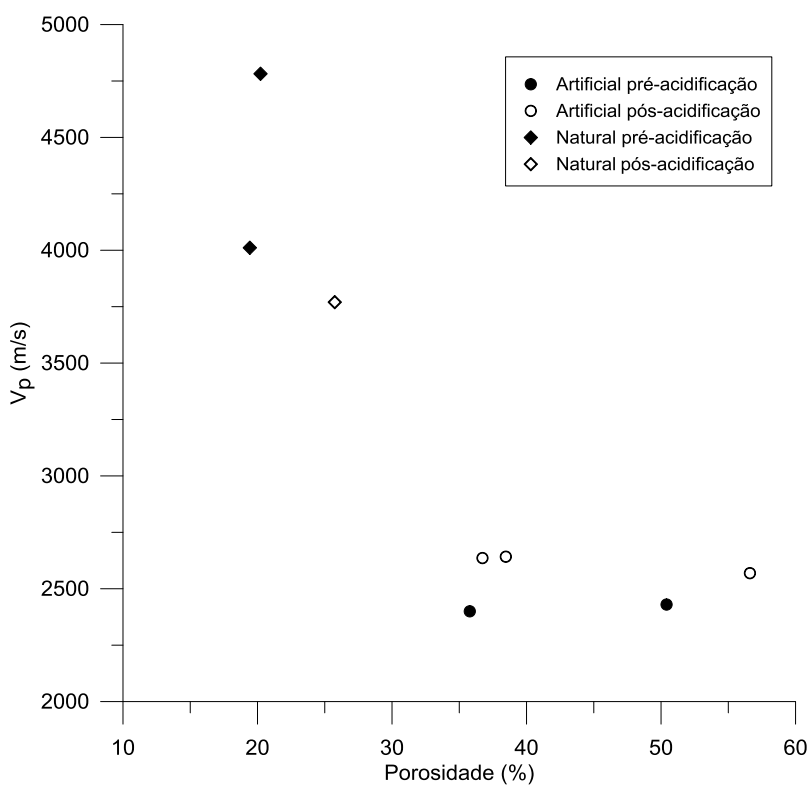

Figura 6 - Relação entre $V_{P}$ e porosidade a $20 \mathrm{MPa}$, antes e após a acidificação.

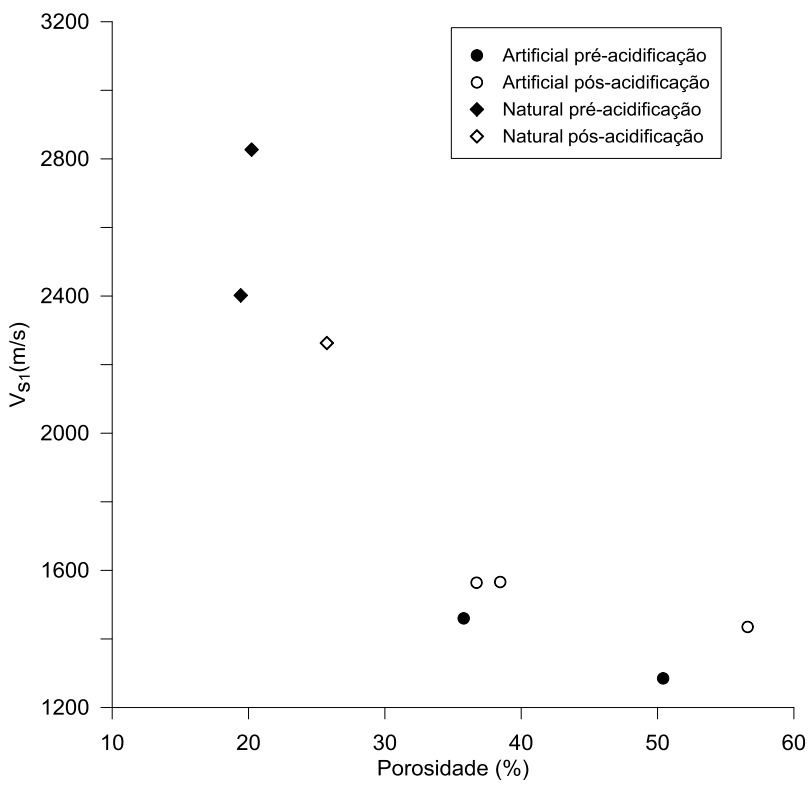

Figura 7 - Relação entre $V_{S 1}$ e porosidade a $20 \mathrm{MPa}$, antes e após a acidificação. 


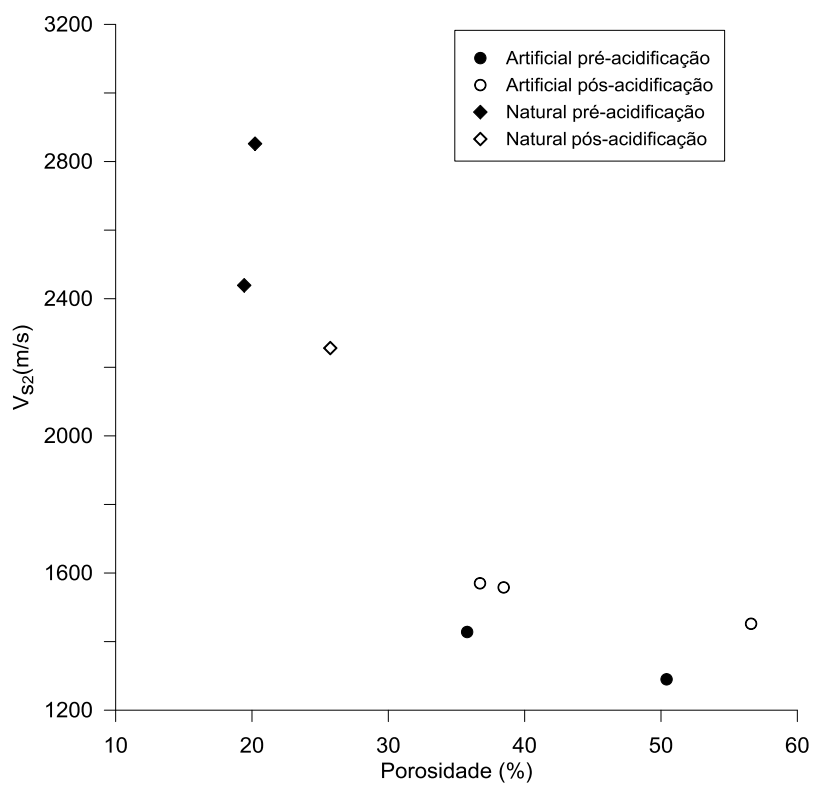

Figura 8 - Relação entre $V_{\mathrm{S} 2}$ e porosidade a $20 \mathrm{MPa}$, antes e após a acidificação.

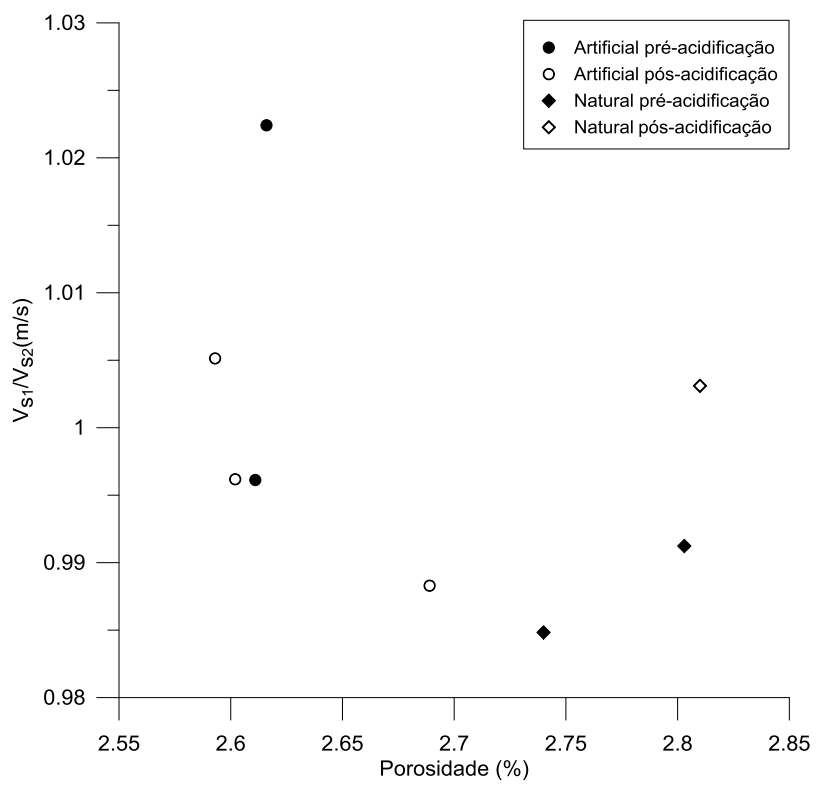

Figura 9 - Relação entre $V_{S 1} / V_{S 2}$ e porosidade a $20 \mathrm{MPa}$, antes e após a acidificação.

As figuras 12, 13 e 14 apresentam a variação dos módulos elásticos com a porosidade, antes e após a aplicação do processo de acidificação. Vê-se dessas figuras que a redução dos módulos foi diretamente proporcional ao aumento da porosidade devido à acidificação, pois as amostras acidificadas se comportam de acordo com a mesma linha de tendência das amostras antes da acidificação

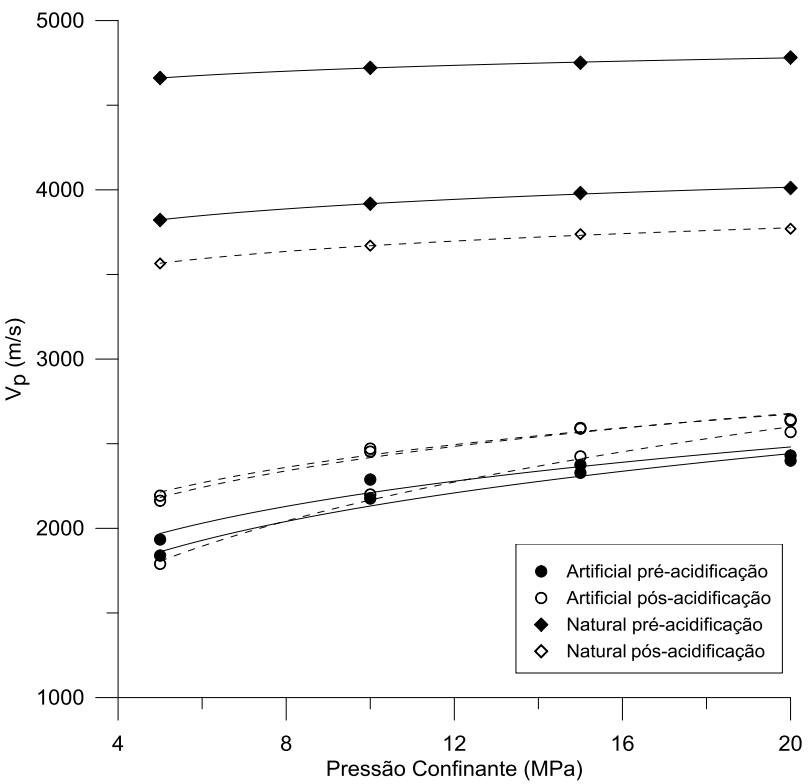

Figura 10 - Relação entre $V_{p}$ e pressão confinante antes e após a acidificação.

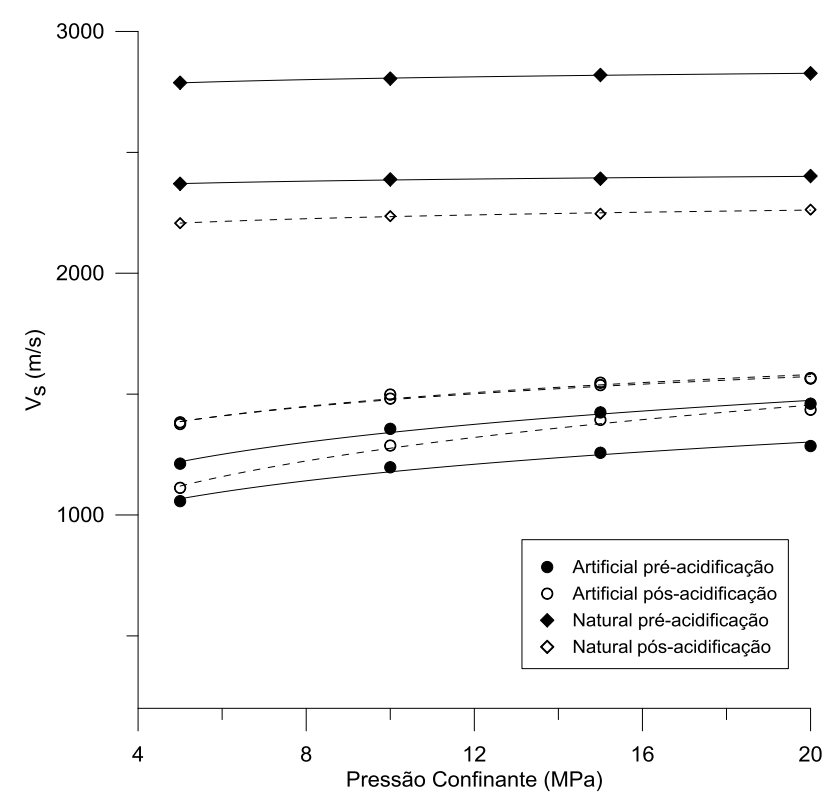

Figura 11 - Relação entre $V_{S}$ e pressão confinante antes e após a acidificação.

A Figura 15 apresenta a relação entre a razão de Poisson, medida a $20 \mathrm{MPa}$, e a porosidade. De modo geral, se observa que a razão de Poisson apresenta uma relação diretamente proporcional com a porosidade. Como o processo de acidificação aumenta a porosidade, consequentemente tende a aumentar a razão de Poisson. 


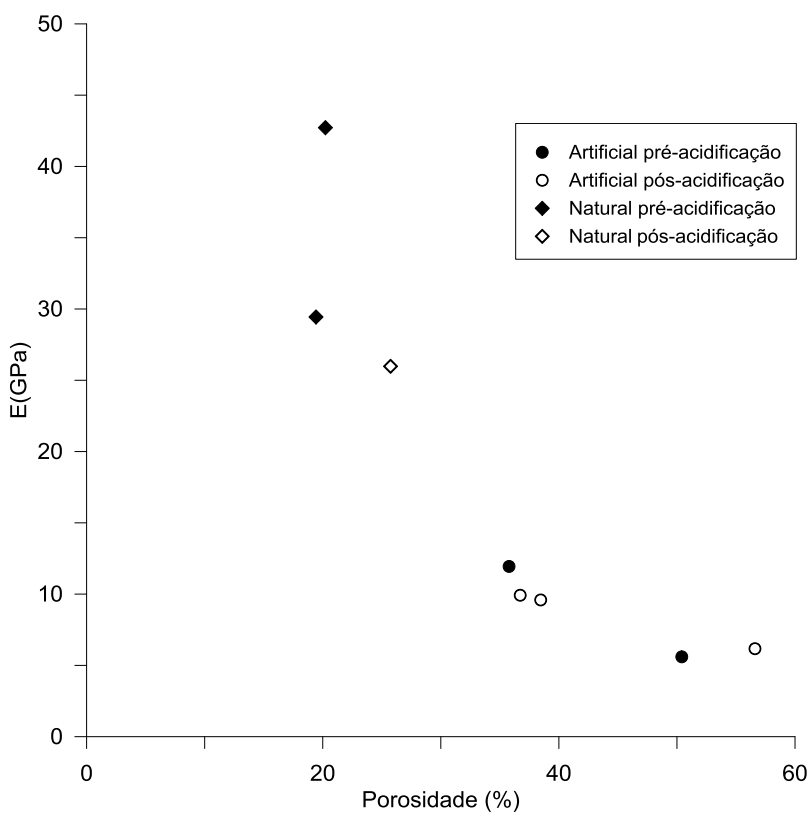

Figura 12 - Relação entre o módulo de Young e porosidade a $20 \mathrm{MPa}$, antes e após a acidificação.

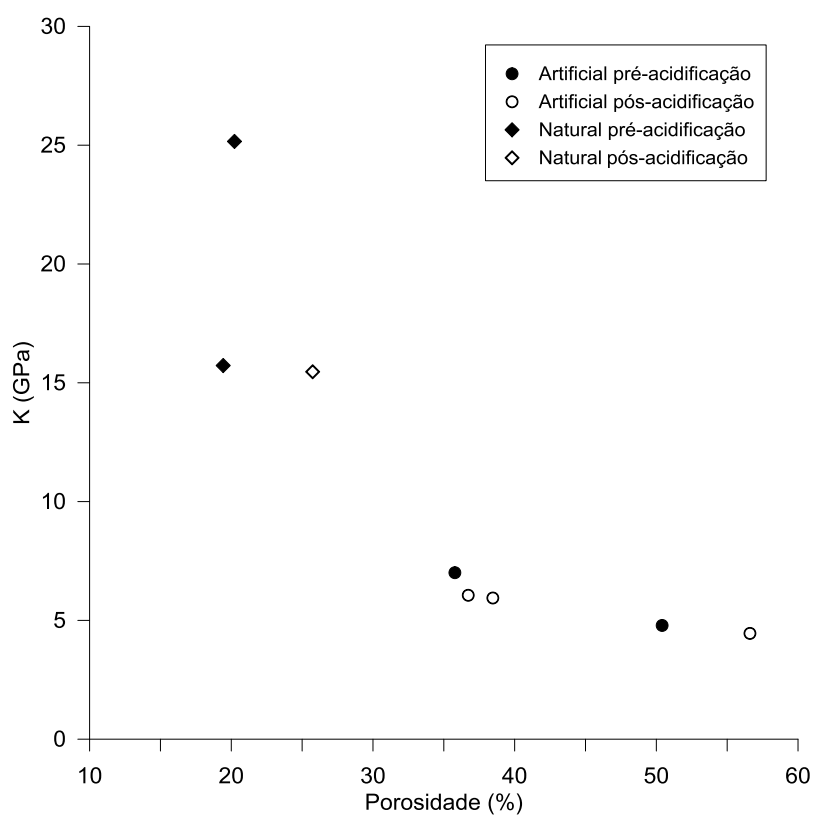

Figura 13 - Relação entre 0 módulo de incompressibilidade e porosidade a $20 \mathrm{MPa}$, antes e após a acidificação.

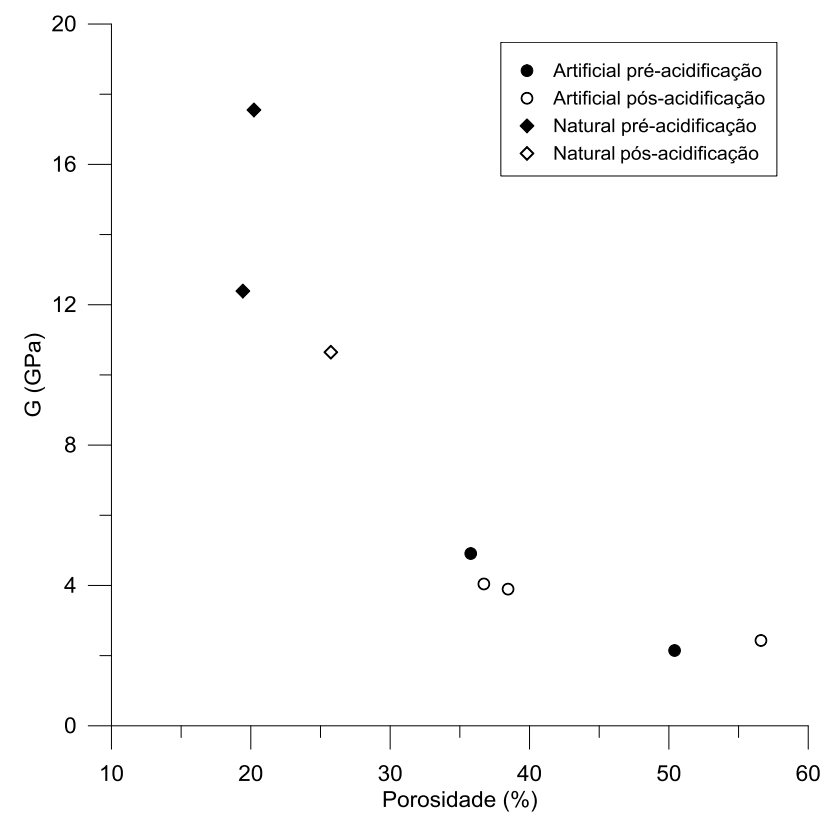

Figura 14 - Relação entre módulo de cisalhamento e porosidade a $20 \mathrm{MPa}$, antes e após a acidificação

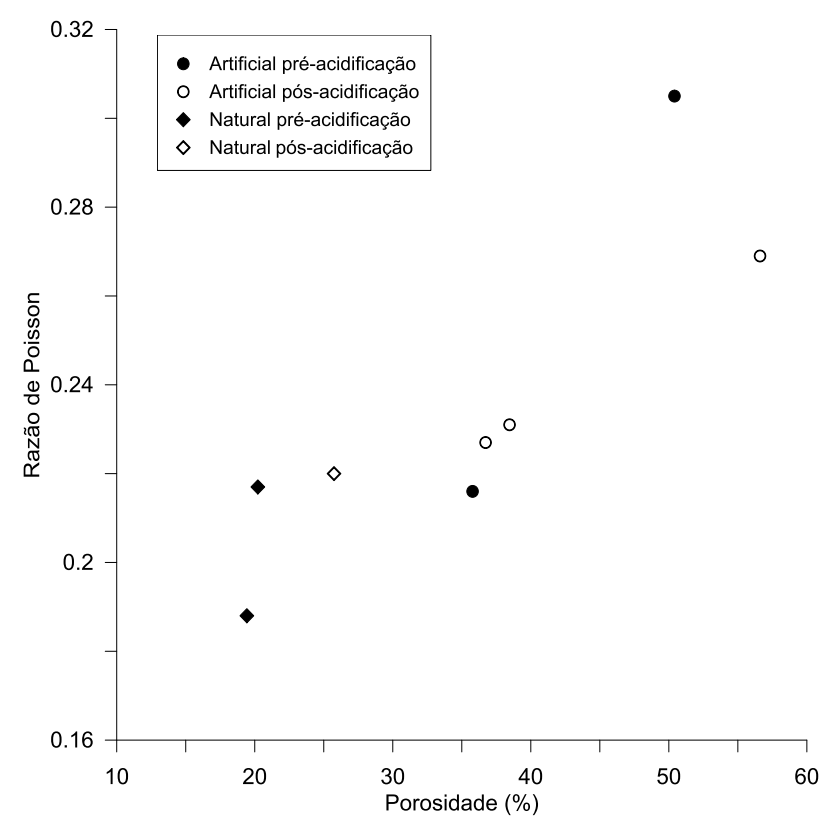

Figura 15 - Relação entre a razão de Poisson e porosidade a $20 \mathrm{MPa}$, antes e após a acidificação. 


\section{Conclusões}

Neste trabalho foram medidas as propriedades petrofísicas de amostras carbonáticas naturais e artificiais antes e após um processo de acidificação de matriz. Para todas as amostras houve aumento das porosidades e das permeabilidades medidas após a acidificação. Nas amostras naturais houve uma redução nas velocidades das ondas elásticas, mas as artificiais apresentaram velocidades ligeiramente superiores. Houve ainda redução dos valores dos módulos elásticos da amostra natural após a acidificação. Para as amostras artificiais os módulos elásticos se mantiveram aproximadamente constantes. Todas as amostras apresentam um aumento da razão de Poisson com o aumento da porosidade e são isotrópicas.

\section{Agradecimentos}

Os autores agradecem aos convênios firmados entre a PETROBRAS e as Universidades Federais de Campina Grande e de Pernambuco, através da Rede Carmod, que permitiram a realização deste trabalho.

\section{Referências}

Avseth, P.; Mukerji, T., Mavko, G., 2005. Quantitative Seismic Interpretation. Applying Rock Physics Tools to Reduce Interpretation Risk. Cambridge University Press, $359 \mathrm{pp}$.

Bourbié, T.; Coussy, O.; Zinszner, B.,1987. Acoustics of porous media. Éditions Technip. Paris.

Economides, M. J.; Hill, A. D.; Ehlig-Economides, C., 1994. Petroleum Production Systems. Prentice Hall PTR. New Jersey, 611 pp.

Mavko, G.; Mukerji, T.; Dvorkin, J., 2003. The Rock Physics Handbook. Tools for Seismic Analysis in Porous Media. Cambridge University Press, 329 pp.

Tiab, D.; Donaldson, E. C., 2004. Petrophysics. Theory and Practice of Measuring Reservoir Rock and Fluid Transport Properties. Elsevier, 889 pp.

Wang, Z.; Nur, A. (Eds.), 2000. Seismic and Acoustic Velocities in Reservoir Rocks. Geophysics Reprint Series, Volume 3. Society of Exploration Geophysicists, 633 pp. 